Aim(s)/objectives To examine the prevalence and meanings of genito-urinary symptoms and the impact on non-attendance at sexual health clinics among people in Britain.

Methods An explanatory sequential mixed methods study design was used to estimate symptom and clinic non-attendance prevalences using data from 8,947 sexually-experienced women and men aged 16-44 years who participated in Britain's third National Survey of Sexual Attitudes and Lifestyles (Natsal-3). We conducted follow-up semi-structured interviews with Natsal-3 participants $(n=27)$ who reported current or recent symptoms and had never attended a clinic, in order to explore STI perceptions, symptom meanings and care-seeking behaviour.

Results Prevalence of experiencing symptom(s) in the last month was 21.6\% (95\% CI 20.4-22.9\%) among women and 5.6\% (95\% CI 4.9-6.6\%) among men, of whom $86.3 \%$ (95\% CI 84.2-88.1) reported not having attended a sexual health clinic in the past year. Bodily changes were not always viewed as symptoms and perceived potential causes were diverse, causing strong emotional responses. Individuals normalised, concealed and/or distanced their experiences from STIs. GPs were the preferred service provider although not all participants perceived a need for care.

Discussion/conclusion Symptoms are more commonly reported by women although both women and men may benefit from interventions targeting symptom normalisation and concealment. Good links between services will facilitate efficient and appropriate care-seeking and service delivery.

\section{P068 INEQUALITIES IN SEXUALLY TRANSMITTED INFECTION RISK AMONG BLACK AND MINORITY ETHNIC MEN WHO HAVE SEX WITH MEN IN ENGLAND}

Hamish Mohammed*, Martina Furegato, Gwenda Hughes. Public Health England, London, UK

\subsection{6/sextrans-2016-052718.122}

Background/introduction Sexually transmitted infection (STI) diagnoses are increasing in men who have sex with men (MSM) in England. While black and minority ethnic (BME) populations bear a disproportionate burden of STIs overall, it is unclear whether this inequality persists among MSM.

Aim(s)/objectives To assess the likelihood of an STI diagnosis among BME MSM relative to other MSM attending genitourinary medicine (GUM) clinics in England.

Methods We included data from the GUM clinic activity dataset (GUMCADv2), the national STI surveillance system in England. All attendances by MSM in 2014 were analysed using univariate and multivariable generalised estimating equations logistic regression. Separate models, adjusted for age, sexual orientation (homosexual/bisexual), residence (London/non-London), arealevel deprivation, HIV positivity and history of HIV testing in the past year, were run for each STI.

Results BME men accounted for 5.6\% of the 326,820 attendances by MSM in 2014. An STI was diagnosed at $12.5 \%$ of attendances by MSM, ranging from $11.1 \%$ in Asian non-Indian/ Pakistani/Bangladeshi to $17.7 \%$ in mixed white and black African MSM. Compared to white British MSM, black Caribbean MSM were most likely to be diagnosed with chlamydia (aOR [95\% $\mathrm{CI}]: 1.34$ [1.18-1.52]) and rectal gonorrhoea (1.31 [1.08-1.60]), while those of mixed white and black African ethnicity were most likely to be newly diagnosed with HIV (1.90 [1.14-3.17]).
Discussion/conclusion Among MSM attending GUM services, BME MSM are most likely to be diagnosed with bacterial STIs and HIV. Culturally appropriate prevention messages must be developed to address this inequality and reduce the higher burden of STIs among BME MSM.

\section{P069 WHAT IMPACT HAS TENDERING HAD ON TRAINEES? THE RESULTS OF A NATIONAL SURVEY OF TRAINEES AND NEWLY APPOINTED CONSULTANTS BY BASHH TRAINEES COLLABORATIVE FOR AUDIT, RESEARCH AND QUALITY IMPROVEMENT PROJECTS}

${ }^{1}$ Helen Wiggins, ${ }^{2}$ Anna Hartley*${ }^{*}{ }^{3}$ Nadia Ahmed, ${ }^{4}$ Emily Clarke, ${ }^{4}$ Elizabeth Foley, ${ }^{5,6}$ Elizabeth Carlin, ${ }^{3}$ Laura Waters. ${ }^{1}$ Chelsea and Westminster Hospital NHS Foundation Trust, London, UK; ${ }^{2}$ Barts Health NHS Trust, London, UK; ${ }^{3}$ Central and North West London NHS Foundation Trust, London, UK; ${ }^{4}$ Solent NHS Trust, Hampshire, UK; ${ }^{5}$ Sherwood Forest Hospitals NHS Foundation Trust, Nottinghamshire, UK; ${ }^{6}$ Nottingham University Hospitals NHS Trust, Nottinghamshire, UK

\subsection{6/sextrans-2016-052718.123}

Background/introduction In April 2013, local authorities gained responsibility for commissioning services for sexual health in England. With many services going to tender and resultant change in services or service provider, there is anecdotal evidence that this has impacted on the education, training and morale of genitourinary medicine (GUM) trainees.

Aim(s)/objectives To evaluate the impact of tendering on GUM trainees.

Methods An electronic survey designed by the British Association for Sexual Health and HIV Trainees' Collaborative for Audit, Research and Quality Improvement Projects (T-CARQ) was distributed to GUM trainees and newly appointed consultants.

Results 82 individuals responded, (74\% GUM trainees, 25\% newly appointed consultants, 1\% Locum appointed for Service). $63 \%(45 / 72)$ had experience of training within a service which was being tendered. Of these, 59\% (24/41) felt their training was not considered and 20\% (8/41) felt that it was. 44\% (18/41) felt adequately supported. $30 \%(12 / 40)$ reported active participation in the tendering process. On a scale of 0 (no impact) to 5 (major impact), the median score for impact of tendering on training was 2 . The positive/negative impact of tendering on different training elements was rated; other than management experience the overall impact on all parameters was negative namely morale, senior support and education.

Discussion/conclusion This survey describes the variable impact of service tendering on GUM training. Our recommendations for maintaining training standards despite tendering include: actively involving trainees and education partners, inclusion of specialist GUM training in service specifications, development of guidance for commissioners and services for the management of GUM training within tendering.

\section{P070 'CHEMSEX' WITHIN MEN WHO HAVE SEX WITH MEN (MSM): HOW BIG IS THE PROBLEM OUTSIDE MAJOR CONURBATIONS?}

\footnotetext{
${ }^{1,2}$ Helen Wiggins, ${ }^{2}$ Helen Mebrahtu* ${ }^{*}{ }^{1}$ Ann Sullivan, ${ }^{2,3}$ Nigel Field, ${ }^{2}$ Gwenda Hughes. ${ }^{1}$ Chelsea and Westminster Hospital NHS Foundation Trust, London, UK; ${ }^{2}$ Public Health England, London, UK; ${ }^{3} \mathrm{UCL}$ Research Department of Infection and Public Health, London, UK
}

10.1136/sextrans-2016-052718.124 
Abstract P070 Table 1 Frequency of chemsex consultations reported by English clinics split into urban/rural category ( $\mathrm{n}=$ number of clinics):

\begin{tabular}{llllll}
\hline $\begin{array}{l}\text { Frequency of Chemsex } \\
\text { Consultations }\end{array}$ & $\begin{array}{l}\text { Group A clinics } \\
\text { (urban conurbation) } \mathbf{n}(\%)\end{array}$ & $\begin{array}{l}\text { Group B clinics } \\
\text { (Urban + city/town) } \mathbf{n}(\%)\end{array}$ & $\begin{array}{l}\text { Group C Clinics } \\
\text { (Urban + rural) } \mathbf{n}(\%)\end{array}$ & $\begin{array}{l}\text { Group D clinics } \\
\text { (Non-urban) } \mathbf{n}(\%)\end{array}$ & $\begin{array}{l}\text { Total } \mathbf{n} \\
\text { P value }\end{array}$ \\
\hline Never & $7(19 \%)$ & $5(12.5 \%)$ & $3(30 \%)$ & $4(27 \%)$ & 19 \\
Monthly or less & $16(44 \%)$ & $28(70 \%)$ & $5(50 \%)$ & $8(53 \%)$ & 57 \\
Weekly & $10(28 \%)$ & $5(12.5 \%)$ & $2(20 \%)$ & $3(20 \%)$ & 20 \\
At least daily & $3(8 \%)$ & $2(5 \%)$ & 0 & 0 & 5 \\
Total & 36 & 40 & 10 & 15 & 101 \\
\hline
\end{tabular}

Background/introduction Sexualised substance use (chemsex) amongst men who have sex with men is well documented in some areas (London, Brighton, Manchester), and associated with high-risk sexual practices and acquisition of sexually transmitted infections.

Aim(s)/objectives To explore demand for chemsex services in UK GUM clinics, including outside major conurbations

Methods An online survey was distributed to clinical staff in GUM clinics across the UK. Analysis at clinic level was undertaken for England, with clinics split into 4 categories: (A) urban conurbation, (B) urban with city/town, (C) urban with significant rural, and (D) non-urban.

Results 357 individuals responded from 152 clinics, 90\% were from England. Country-specific clinic response rates were $63 \%$ $(135 / 214)$ in England, 80\% (4/5) Northern Ireland (NI), 8\% (3/ 39) Scotland and $83 \%(10 / 12)$ Wales. $82 \%(227 / 278)$ of respondents reported seeing patients who disclosed chemsex (82\% England (205/251), 83\% NI (5/6), 75\% Scotland (6/8), $85 \%$ Wales (11/13)), and there was broad consensus that chemsex services (86\%) and training were needed (98\%). 64\% (68/ 106) of clinics reported routinely asking selected patients about chemsex, 10\% (11/106) asked all patients, and the remainder did not ask. Although the proportion of clinics seeing chemsex and the frequency of chemsex consultations was reported to be higher in more urban settings, differences were not significant and many clinics in rural areas reported chemsex consultations (Table 1).

Discussion/conclusion Chemsex consultations occur in most GUM clinics across the UK albeit to varying degrees. These data suggest a widespread need for specialist chemsex services and training.

\section{P071 COST EFFICACY SAVINGS ON SEROLOGICAL FOLLOW UP FOR SYPHILIS AT AN URBAN SEXUAL HEALTH CLINIC}

Rebecca Gilson. Chalmers Centre, Edinburgh, UK

\subsection{6/sextrans-2016-052718.125}

Background/introduction General Practitioners (GPs) in Lothian are requesting syphilis serology in $65 \%$ of individuals being tested for HIV. Adding syphilis to the remaining 35\% would cost around $£ 7000$. In Edinburgh full serology (IgG, RPR, TPPA, IgM) is performed in all with a previous syphilis diagnosis. HIV positive individuals are tested 6 monthly. BASHH 2015 Syphilis Guidelines recommend RPR follow up and annual monitoring in HIV positive individuals. The aim was to evaluate if full serological screening was appropriate and whether cost savings could be made.

Methods One hundred individuals with full serological testing for syphilis, 30/9/15 to 29/10/15. Age, risk group, HIV status, stage of infection, PCR, treatment, symptoms, follow up and infection risks were collated.

Results 88 male, 12 female. Twenty one early infection (all positive RPR), 4 re infection (all rise in RPR), 7 late latent and 54 treated infection. Forty seven HIV positive. Of these 14 (21\%) had no ongoing risks and 16 (34\%) had ongoing risks, longstanding RPR 0. Forty HIV negative. Twenty four (60\%) were MSM with treated STS, and a longstanding RPR 0.

Recommendations Testing should be annual RPR in HIV positive individuals with no ongoing risks. In those with ongoing risks RPR alone sufficient for monitoring. All with re infection would have been picked up on RPR. In HIV negative individuals, most had ongoing risks but a longstanding RPR 0 . Monitoring with RPR only would have diagnosed all re infections.

Discussion It was difficult to vary testing based on risk assessment and concerns that RPR only may miss prozone. However, there was agreement that IgM should no longer be performed. At $£ 3.77 /$ test approximately $£ 377 /$ month would be saved in this group alone. This would apply to all other testing with considerable cost savings

\section{P072 EQUITY OF ACCESS TO ONLINE SEXUALLY TRANSMITTED INFECTION SELF-SAMPLING SERVICES IN LAMBETH AND SOUTHWARK: AN EARLY VIEW OF THE DATA}

${ }^{1}$ Sharmani Barnard*, ${ }^{2}$ Katy Turner, ${ }^{2}$ Katherine Looker, ${ }^{1}$ loannis Bakolis, ${ }^{3}$ Caroline Free, ${ }^{1}$ Paula Baraitser. 'King's College London, London, UK; ' University of Bristol, Bristol, UK; ${ }^{3}$ London School of Hygiene and Tropical Medicine, London, UK

10.1136/sextrans-2016-052718.126

Background In 2015, free access to online services for STI selfsampling was made available to residents in Lambeth and Southwark. Little is known about who accesses online services within these boroughs and whether access is equitable between demographic groups.

Aims To describe the demographic factors associated with use of online services for STI self-sampling.

Methods A cross-sectional analysis of routinely collected data from April to October 2015 for online and sexual health clinics in Lambeth and Southwark. We included residents who attended sexual health clinics or used online sexual health services for basic STI testing and were over the age of 16 . Data were analysed by means of logistic regression.

Results A total of 9,496 basic STI testing services were delivered, 6,697 (70.52\%) were delivered in clinics while 2,799 $(29.48 \%)$ were delivered online. Descriptive data for service use by demographic group is available in Table 1 . When compared to residents aged 16-20 years old, residents aged 21-24 $(\mathrm{OR}=1.93, \mathrm{p} \leq 0.001)$, and $25-30(\mathrm{OR}=2.17, \mathrm{p} \leq 0.001)$ 